Casos Clínicos

Arch. Esp. Urol., 60, 10 (1.209-1.212), 2007

\section{CARCINOMA URETERAL. EL CONVIDADO DE PIEDRA DE LA PATOLOGÍA UROLÓGICA}

Francisco Javier Torres Gómez, Francisco Javier Torres Olivera' y M. Díaz Delgado?.

Servicios de Anatomía Patológica. Hospital de Alta Resolución de Utrera. Sevilla. Hospital Universitario Virgen Macarena de Sevilla' y Hospital General de Mérida² España.

Resumen.- OBJETIVO: Si bien la citología de orina juega un importante papel en el diagnóstico de neoplasias de vías urinarias bajas, deberá ser auxiliada por otras pruebas diagnósticas en el diagnóstico de las neoplasias del tracto superior.

MÉTODOS: Presentamos un caso de carcinoma urotelial de uréter sincrónico con neoplasia papilar y carcinoma in situ vesicales.
RESULTADOS: La positividad persistente de estudios citológicos de orina en pacientes tratados de lesiones en vías inferiores sin evidencias de imagen de lesión a este nivel debe despertar la sospecha de lesiones de vías superiores.

CONCLUSIONES: El carcinoma de uréter es una neoplasia agresiva que puede beneficiarse de un diagnóstico no tardío, acción que a su vez repercutirá en la funcionalidad del riñón homolateral.

Palabras clave: Carcinoma. Uréter. Citología urinaria.

Summary.- OBJECTIVE: Although urine cytology plays an important role in the diagnosis of lower urinary tract neoplasias, it should be complemented with other diagnostic tests for the diagnosis of upper urinary tract tumors.

METHODS: We present one case of synchronic transitional cell carcinoma of the ureter and bladder papilary neoplasia and carcinoma in situ.

RESULTS: The persistent positivity of urine cytology in patients treated for lower urinary tract lesions without evidence of lesion in that level should raise the suspicion of upper urinary tract lesions.

CONCLUSIONS: Ureteral carcinoma is an aggressive neoplasia and early diagnosis may be beneficial and also have repercussions in the ipsilateral kidney function.

Keywords: Carcinoma. Ureter. Urine cytology.

\section{INTRODUCCIÓN}

Si bien la citología urinaria desempeña un papel inestimable en el diagnóstico y seguimiento de neoplasias del tracto urinario, éste necesita ser asistido en ocasiones por métodos diagnósticos complementarios de segundo nivel con el fin de intentar localizar el origen lesional. En ocasiones, como es el caso de las neoplasias de uréter, estos métodos secundarios jugarán un papel diagnóstico principal en la identificación de tal localización siendo la sospecha clínica en la mayoría de los casos la misma positividad repetida de los estudios citológicos de orina tras haber realizado un descarte diagnóstico y/o terapéutico de una localización más distal, considerando esta última más frecuente $y$, por tanto, objetivo del despistaje primario. 


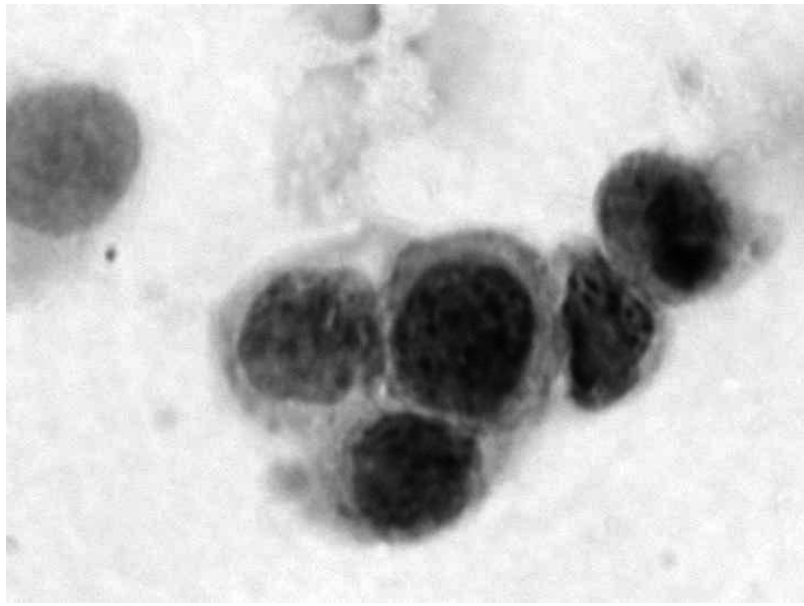

FIGURA 1. Carcinoma urotelial. Detalle citológico. Pap.

\section{CASO CLÍNICO}

Paciente varón de 80 años con clínica de prostatismo y hematuria al que se le realiza un estudio citológico de orina, observándose grupos bidimensionales pseudopapilares de células con intensa atipia, evidenciada por un aumento del tamaño nuclear, hipercromasia, desproporción núcleo-citoplasmática y por la presencia de nucleolos (Figura 1). Algunas células mostraban rasgos plasmacitoides y en la mayoría de las mismas se observaba irregularidad de los contornos del núcleo, rodeando una cromatina de predominio granular. Asimismo se observaron placas bidimensionales de gran tamaño y orangofília donde las células mostraban en esencia características similares a las ya descritas. Tales hallazgos condicionaron la realización de una resección transuretral. El estudio histológico del material obtenido permitió identificar una lesión neoplásica de

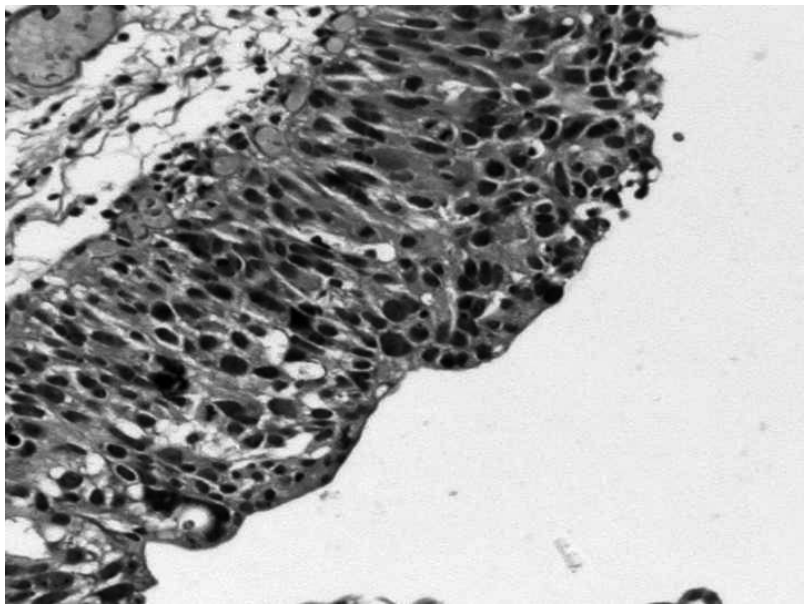

FIGURA 2. Carcinoma urotelial in situ. HE. 20x.

alto grado limitada por la membrana basal urotelial. Dicha lesión estaba constituida por la estratificación, con pérdida de la polaridad, de células con atipia de alto grado en diversos fragmentos (Figura 2), en aposición con otros con arquitectura papilar que albergaban una lesión igualmente neoplásica (Figuras 3 y 4). Así, se emitió el diagnóstico de carcinoma urotelial in situ y papilar de alto grado asociados. Posteriormente se realizó una citología urinaria de control observándose de nuevo celularidad neoplásica (Figura 5). Ante este hallazgo se le realizó al paciente una cistoscopia, la cual resultó negativa. Se repitió el estudio citológico y volvió a ser positivo. Ante la sospecha de carcinoma de vías urinarias superiores se realizó una ureterografía retrógrada de ambos uréteres comprobándose la presencia de una lesión estenosante en el uréter proximal derecho. Finalmente se realizó una nefrectomía con ureterectomía homolateral siendo negativas las citologías urinarias de

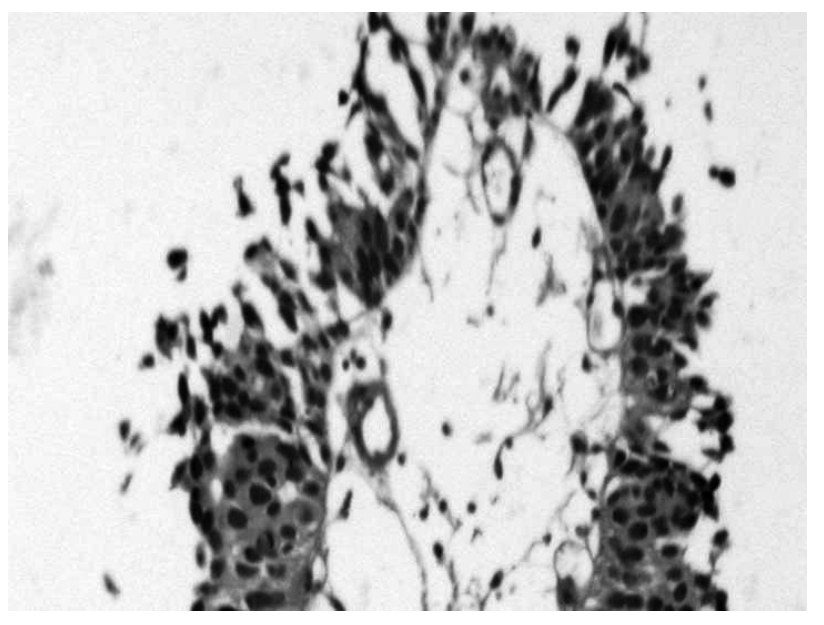

FIGURA 3. Carcinoma papilar urotelial. HE. 10x.

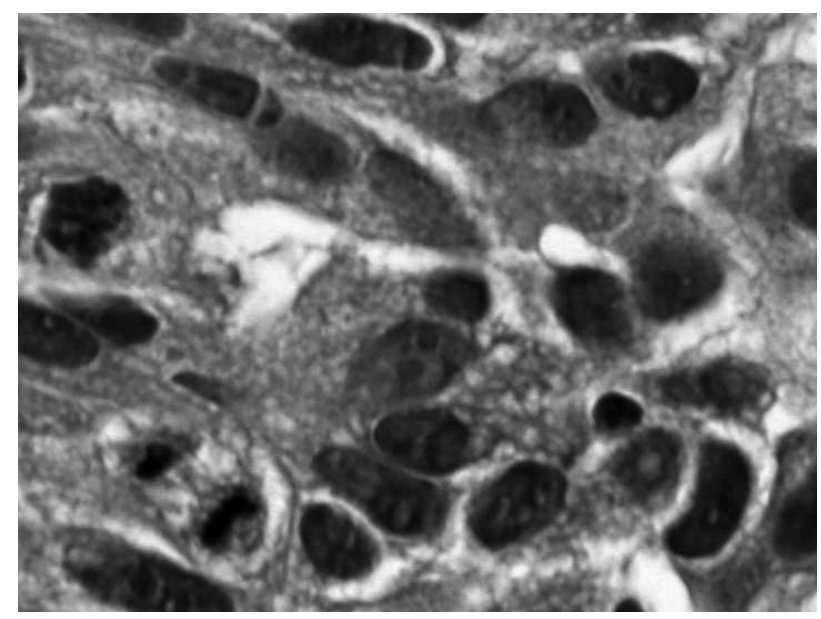

FIGURA 4. Carcinoma papilar urotelial de alto grado. Detalle citológico. HE. 40x. 


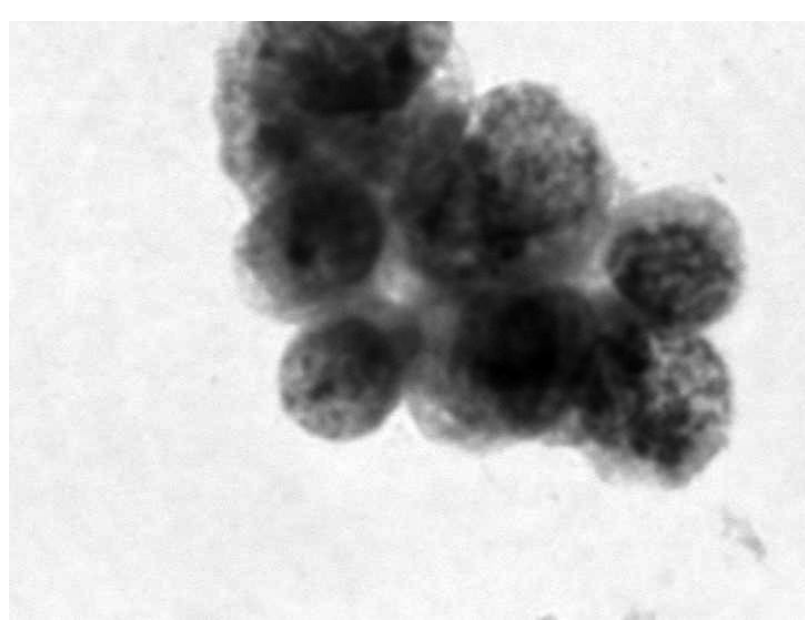

FIGURA 5. Carcinoma urotelial. Citología de control. Pap.

control obtenidas tras la intervención quirúrgica. El estudio histológico del uréter permitió observar una lesión papilar afectando a la práctica totalidad de la circunferencia del uréter (Figuras 6 y 7), midiendo $2,5 \mathrm{~cm}$. de dimensión máxima. La atipia citológica observada era superponible a la de los estudios citológicos previos (Figura 8). El riñón mostró hallazgos de nefritis intersticial. En consecuencia, se emitió el diagnóstico de carcinoma urotelial de alto grado multifocal asociado a carcinoma in situ vesical. Tras 2 años de seguimiento el paciente permanece libre de síntomas.

\section{DISCUSIÓN}

El carcinoma urotelial es una de las neoplasias que con más frecuencia se asocia a multifocalidad. En concreto, la asociación de una localización sincrónica vesical y ureteral aparece reflejada en la literatura en un porcentaje de hasta el 10-15\% de los casos. Las características epidemiológicas de ambas localizaciones son similares en cuanto a clínica, sexo, tipo histológico y pronóstico. El carcinoma ureteral por separado es una neoplasia relativamente infrecuente $15 \%$ aproximadamente de las neoplasias del sistema urinario) que se localiza principalmente en los extremos proximal y distal (nuestro caso mostraba una localización proximal) correspondiendo más del $90 \%$ de los casos a tumores uroteliales (2). Existe un amplio abanico de neoplasias ureterales no uroteliales si bien su frecuencia es prácticamente anecdótica debido al alto porcentaje de neoplasias derivadas del urotelio, principal grupo de neoplasias a este nivel (3).

Su debut clínico suele ser con hematuria (90\%) siendo el dolor en el flanco homolateral el segundo síntoma en frecuencia (20\%). Como antecedentes clínicos de interés que se relacionen con el desarrollo de esta neoplasia se suele destacar el papel de drogas tales como la fenacetina así como la propia presencia de cálculos, probablemente debido al efecto irritativo de los mismos sobre el urotelio. También parece estar probado el papel del consumo crónico y elevado de tabaco así como la exposición ocupacional a sustancias tales como las utilizadas en la industria del plástico y la petroquímica. La clínica, citología y cistoscopia tienen una baja rentabilidad diagnóstica por separado en el diagnóstico del carcinoma ureteral, que aumenta si se agrupan en un triple test. En cualquier caso será la positividad repetida de estudios de citología urinaria la que oriente hacia el verdadero diagnóstico. Estudios tales como la ureterografía retrógrada... serán más específicos pero sólo se recurrirá a los mismos en casos de una sospecha razonable. Está comprobado que la asociación de un carcinoma in situ urotelial empeora el pronóstico del paciente. En cuanto a este último diagnóstico es importante destacar la mayor rentabilidad diagnóstica de la citología urinaria en comparación con la cistoscopia y

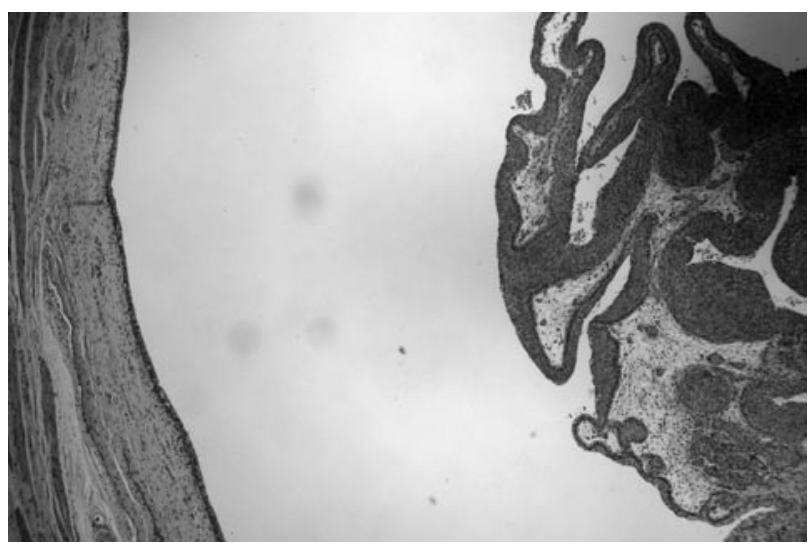

FIGURA 6. Carcinoma urotelial papilar de uréter. Imagen panorámica. HE. $4 x$

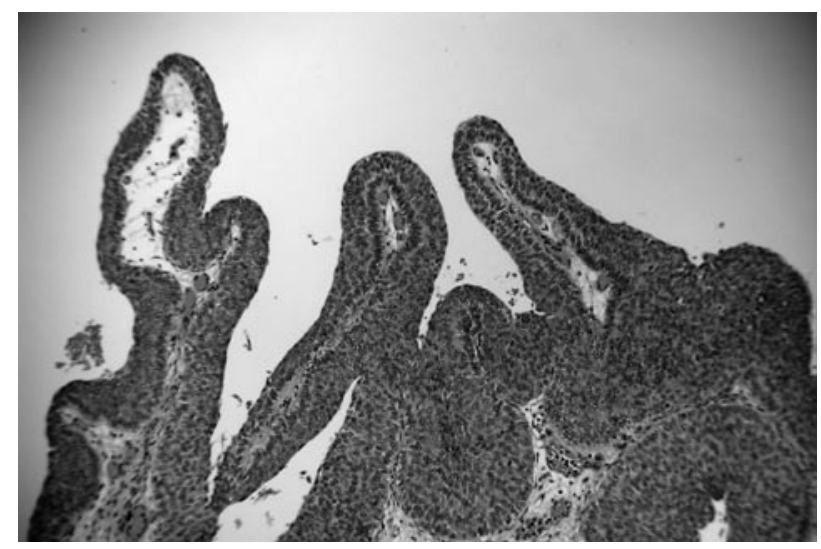

FIGURA 7. Carcinoma urotelial papilar de uréter. Detalle de las papilas. HE. 10x. 
biopsia pues muchas de estas lesiones son planas y pasan desapercibidas al estudio óptico; entre las limitaciones del estudio citológico del carcinoma in situ tenemos que hacer referencia a la imposibilidad de distinguir una lesión in situ de una infiltrante. Así, ambas muestran núcleos excéntricos con variable pleomorfismo y alto índice núcleo-citoplasmático, los frotis son bastante celulares y se observa una llamativa discohesión celular (3).

En cuanto al diagnóstico definitivo y su clasificación en el grupo predefinido más adecuado dependerá de un concienzudo estudio histológico; éste podrá realizarse en material obtenido mediante RTU si bien la pieza de extirpación quirúrgica (ureterectomía) ofrecerá la posibilidad de valorar la lesión no sólo desde el punto de vista microscópico sino también macroscópico y con ello podrá establecerse con precisión el nivel de invasión de la neoplasia. Del mismo modo podrán describirse características tan variopintas como la arquitectura superficial (papilar, plana, nodular), la presencia de ulceración y/o áreas necróticas, la presencia de focos tumorales no descritos previamente y la confirmación de alteraciones ureterales no neoplásicas tales como hidrouréter, hidronefrosis y hasta la identificación de estructuras calculosas. La histología no difiere de la encontrada en las lesiones de vejiga y así los mismos grupos y tipos han sido descritos por igual en ambas localizaciones. Es por ello por lo que ambas lesiones serán gradadas con los mismos criterios.

En nuestro caso convergen una serie de circunstancias que, si bien no son excepcionales, sí son infrecuentes y a la vez nos sirven para ilustrar una situación que según nuestro criterio debe ser tenida en mente antes de afrontar el diagnóstico de una neoplasia, en este caso urotelial, del sistema urinario.

Entre los factores pronósticos más importantes se encontrarían el estadio tumoral y el nivel de invasión de

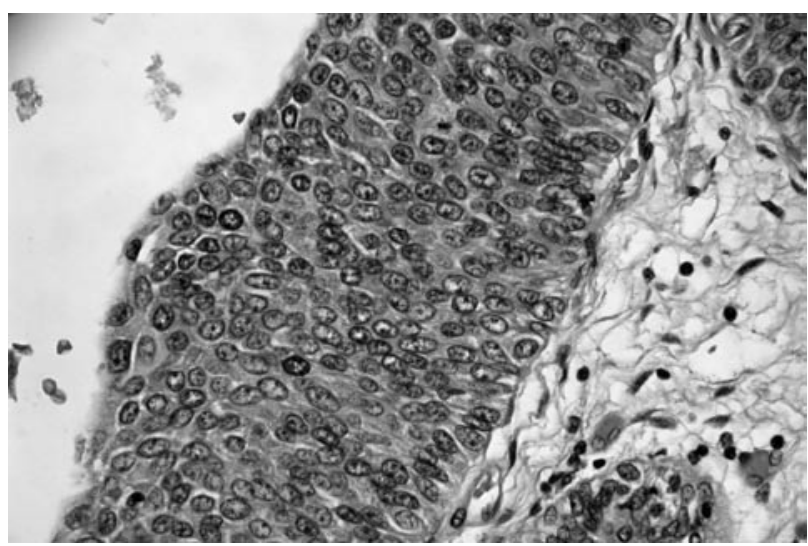

FIGURA 8. Carcinoma urotelial de uréter de alto grado. Detalle citológico. HE. 40x. manera que cuánto mayores sean éstos, mayor será la agresividad del tumor y por tanto peor el pronóstico (1). Por supuesto, este pronóstico será infausto en aquellos casos con extensión linfática o sanguínea. Además, una de las consecuencias del carácter estenosante de la mayor parte de las neoplasias ureterales es la estasis urinaria retrógrada con las consecuencias pertinentes en la función renal. En estadios avanzados se llega a una situación de insuficiencia renal, razón por la cual, en la mayoría de los casos, como el nuestro, la ureterectomía terapéutica lleva asociada una nefrectomía ipsilateral.

Como hemos podido observar, el tratamiento de elección para el carcinoma de uréter es el quirúrgico asociándose en alto número de ocasiones la nefrectomía a la ureterectomía (4). Son varios los estudios que han abordado la utilidad de una terapéutica coadyuvante al tratamiento quirúrgico habiéndose demostrado su utilidad incluso en aquellos casos con diagnóstico de carcinoma in situ. Quizá se pueda pensar que la nefroureterectomía radical es un tratamiento excesivamente agresivo para el tratamiento de lesiones in situ de tal localización y es verdad que un porcentaje de los pacientes será sobretratado si bien se ha demostrado el beneficio estadístico de la aplicación de este procedimiento, más aun cuando cabe la posibilidad de que dicho paciente tenga una lesión invasiva sincrónica que haya pasado desapercibida a los medios diagnósticos prequirúrgicos y pueda ensombrecer el pronóstico (5).

\section{BIBLIOGRAFÍA y LECTURAS RECOMENDADAS ( ${ }^{*}$ lectura de interés $y^{* *}$ lectura fundamental)}

*1. OZSAHIN, M.; ZOUHAIR, A.; VILLA, S. y cols.: "Prognostic factors in urothelial renal pelvis and ureter tumours: A multicentre rare cancer network study. Eur. J. Cancer., 35: 738, 1999.

2. MUÑOZ, J.J.; ELLISON, L.M.: "Upper tract urotelial neoplasms: Incidence and survival during the last two decades". J. Urol., 164: 1523, 2000.

3. OOSTERLINCK, W.: "Ureteral tumor: A specific upper urinary tract transitional cell carcinoma". Eur. Urol., 4: 100, 2006.

4. YUASA, T.; TSUCHIYA, N. y cols.: "Radical nephroureterectomy as initial treatment for carcinoma in situ of upper urinary tract". Urology, 68: 972, 2006.

5. KWAK, C.; LEE, S.E.; JEONG, I.G. y cols.: "Adyuvant systemic chemotherapy in the treatment of patients with invasive transitional cell carcinoma of the upper urinary tract". Urology, 68: 53, 2006.

6. BUSBY, J.E.; BROWN, G.A.; TAMBOLI, P.: "Upper urinary tract tumors with non transitional histology: A single center experience". Urology, 67: 518, 2006. 